\title{
Magnetic properties and microstructure of lanthanum-doped Mn-Al and Mn-Al-C permanent magnets
}

\author{
J. H. HUANG, P. C. KUO, C. H. CHEN \\ Institute of Materials Science and Engineering, National Taiwan University, Taipei, Taiwan
}

$\left(\mathrm{Mn}_{0.54} \mathrm{Al}_{0.46}\right)_{100-x} \mathrm{La}_{x}$ and $\left(\mathrm{Mn}_{0.535} \mathrm{Al}_{0.448} \mathrm{C}_{0.017}\right)_{100-x} \mathrm{La}_{x}$ alloys, with $x$ up to 0.9, were synthesized and examined by powder $\mathrm{X}$-ray diffraction and magnetic measurements. Lattice parameters, Curie temperature, $T_{\mathrm{C}}$, coercivity, $\mathrm{i} H_{\mathrm{c}}$, and saturation magnetization, $M_{\mathrm{s}}$, were determined. Phase analysis revealed that $\mathrm{Al}_{8} \mathrm{LaMn}_{4}$ precipitates were produced due to the lanthanum addition. A slight increase in the $\mathrm{i} H_{c}$ was observed for $x \leq 0.3$ in the cast MnAlLa alloys. No significant changes in lattice parameters and $T_{\mathrm{C}}$ were observed for these lanthanum-doped alloys. For sintered isotropic magnets, which were prepared by conventional powder metallurgy processes, the $\mathrm{i}_{\mathrm{c}}$ was enhanced on doping with lanthanum. The $(\mathrm{BH}) \max$ values were also increased. The increment of $(B H)_{\max }$ was about $16 \%$ for $x=0.3$. Higher lanthanum intensity at grain boundaries was observed on examination of the energy-dispersive $X$-ray spectra (EDX). The reasons for the increase in $i H_{c}$ may be due to the fine precipitates of lanthanum in the grain boundaries.

\section{Introduction}

In the $\mathrm{Mn}-\mathrm{Al}$ system, a ferromagnetic phase occurs in the composition range $67 \mathrm{wt} \%<\mathrm{Mn}<73 \mathrm{wt} \%$ $(51$ at $\%<\mathrm{Mn}<58$ at $\%)$. This ferromagnetic $\tau$ phase can be obtained either by quenching the hightemperature phase $(\varepsilon)$ followed by annealing at about $550^{\circ} \mathrm{C}$, or by cooling the $\varepsilon$-phase at rates of the order of $10^{3}{ }^{\circ} \mathrm{C} \mathrm{min}^{-1}$. The $\tau$-phase is a metastable phase whose structure and magnetic properties have been extensively investigated [1-7]. It has the $\mathrm{AuCuI}$ type structure, and possess high values of the crystallographic anisotropy constant, $K\left(10^{7} \mathrm{erg} \mathrm{cm}^{-3}\right)$ and saturation magnetization, $M_{\mathrm{s}}(\sim 5000 \mathrm{G})$.

Two mechanisms have been proposed for the formation of the magnetic $\tau$-phase $[8,9]$

$$
\begin{aligned}
& \mathrm{hcp}(\varepsilon) \rightarrow \mathrm{B} 19\left(\varepsilon^{\prime}\right) \rightarrow \mathrm{fct}(\tau) \\
& \mathrm{hcp}(\varepsilon) \rightarrow \mathrm{fcc} \rightarrow \mathrm{fct}(\tau)
\end{aligned}
$$

where $\mathrm{hcp}, \mathrm{fcc}, \mathrm{fct}$, and $\mathrm{B} 19$ indicate hexagonal, face-centred-cubic, face-centred-tetragonal, and orthorhombic structure, respectively. However, the usually accepted mechanism is that the high-temperature

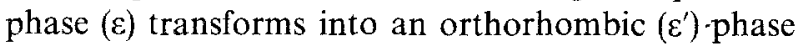
by an ordering reaction and then to a metastable ferromagnetic $\tau$-phase in a martensitic mode [9].

Carbon-doped $\mathrm{Mn}-\mathrm{Al}$ alloy has been found to be more stable in its ferromagnetic phase and to show improved mechanical properties, although it has a lower Curie temperature $\left(280^{\circ} \mathrm{C}\right)$ than undoped alloys $\left(380^{\circ} \mathrm{C}\right)[10]$. It has been reported that the isotropic $\mathrm{Mn}-\mathrm{Al}$ and $\mathrm{Mn}-\mathrm{Al}-\mathrm{C}$ alloys prepared by casting and optimum heat treatment have the following magnetic properties: $B_{\mathrm{r}}=1500 \mathrm{G}, \mathrm{i} H_{\mathrm{c}}=600 \mathrm{Oe}$ and $(B H)_{\max }$ $=0.4 \mathrm{MGOe}$ for $\mathrm{Mn}_{55} \mathrm{Al}_{45}[11] ; B_{\mathrm{r}}=3000 \mathrm{G}$, $\mathrm{i} H_{\mathrm{c}}=1000 \mathrm{Oe}$ and $(B H)_{\max }=0.8 \mathrm{MGOe}$ for $\mathrm{Mn}_{52.9} \mathrm{Al}_{45.4} \mathrm{C}_{1.7}$ [12].

The $\mathrm{Mn}-\mathrm{Al}$ alloy is produced from low-cost raw materials and has a theoretical $(B H)_{\max }$ value of 12 MGOe. It has been extensively studied to improve its magnetic properties. Many techniques have been used to fabricate $\mathrm{Mn}$-Al permanent magnets, such as swaging, rapidly quenching, the powder method and hot extrusion $[2,10,13]$ etc. These studies have shown that the deformation process by hot extrusion produces the best results in improving its magnetic properties. The extruded $\mathrm{Mn}-\mathrm{Al}-\mathrm{C}$ alloys achieve magnetic properties of $B_{\mathrm{r}}=5750 \mathrm{G}, \mathrm{i} H_{\mathrm{c}}=3200 \mathrm{Oe}$ and $(B H)_{\max }=7$ MGOe [10]. However, this hot-extrusion process is critical and somewhat expensive in cost of energy and tool wear. The high magnetic properties obtained in the extruded $\mathrm{Mn}-\mathrm{Al}-\mathrm{C}$ alloy are the result of the high anisotropy, grain-size reduction and carbide precipitations. The addition of elements such as boron, zirconium, titanium, tin, tellurium, tungsten, gallium, phosphorus, etc. [14-16] for $\mathrm{Mn}-\mathrm{Al}$ alloy has also been investigated. However, the addition of rare-earth elements has not been reported. The present paper describes the enhancement of coercivity in lanthanum-doped $\mathrm{Mn}-\mathrm{Al}$ alloys. The magnetic properties of the sintered $\mathrm{Mn}-\mathrm{Al}-\mathrm{La}-\mathrm{C}$ magnets are also reported.

\section{Experimental procedure}

Alloys of $\left(\mathrm{Mn}_{0.54} \mathrm{Al}_{0.46}\right)_{100-x} \mathrm{La}_{x}$ and $\left(\mathrm{Mn}_{0.535} \mathrm{Al}_{0.448}\right.$ $\left.\mathrm{C}_{0.017}\right)_{100-x} \mathrm{La}_{x}$ were prepared from high-purity 
$(99.99 \%)$ manganese, aluminium, carbon and lanthanum by using a high-frequency induction furnace under a protective argon atmosphere. The as-cast samples were homogenized at $1100{ }^{\circ} \mathrm{C}$ for $12 \mathrm{~h}$ to remove segregations in the alloys. The annealing treatment was carried out at a temperature between 450 and $600^{\circ} \mathrm{C}$ to obtain the magnetic $\tau$-phase.

For preparing the isotropic sintered MnAlLa and MnAlCLa permanent magnets, the cast ingots had to be crushed into small pieces, and then pulverized in hammer and ball millers. The fine powders were pressed into cylindrical pellets under a hydrostatic pressure of 5 ton $\mathrm{cm}^{-2}$. The powder compacts were vacuum sintered at a pressure of $10^{-1}$ torr ( 1 torr $=133.322 \mathrm{~Pa}$ ) with a sintering temperature between $1160^{\circ}$ and $1230^{\circ} \mathrm{C}$ for $15 \mathrm{~min}$; then they were solution treated at $1100^{\circ} \mathrm{C}$ for $1 \mathrm{~h}$ and quenched in oil. Finally, they were tempered at $600^{\circ} \mathrm{C}$ to obtain the $\tau$-phase. The microstructure of the annealed specimens was observed after they had been etched in a solution of $6 \%$ hydrochloric acid, $3 \%$ nitric acid, $1 \%$ hydrofluoric acid and $90 \%$ water. The phase constitution and the lattice parameters were determined by X-ray diffraction using a nickel-filtered $\mathrm{Cu} K_{\alpha}$ radiation. Magnetic properties were measured using a $B-H$ loop tracer with a maximum applied field of $20 \mathrm{kOe}$. The Curie temperature, $T_{\mathrm{C}}$, was measured using a vibrating sample magnetometer (VSM).

\section{Results and discussion}

\subsection{Cast alloy}

Powder X-ray diffraction patterns of annealed $\left(\mathrm{Mn}_{0.54} \mathrm{Al}_{0.46}\right)_{100-x} \mathrm{La}_{x}$ samples $(x=0.00,0.14,0.3$, $0.9)$ indicate that the above samples are $\tau$-phase. A second phase, $\mathrm{Al}_{8} \mathrm{LaMn}_{4}$, was found at $x \geq 0.3$, as shown in Fig. 1. The relations between magnetic properties and lanthanum doping of the cast samples is shown in Fig. 2. The saturation magnetization, $M_{\mathrm{s}}$, remains almost constant at $x<0.3$. However, a small increase in coercivity, $\mathrm{i} H_{\mathrm{c}}$, was observed with $x$ up to about 0.3 , above which both the $M_{\mathrm{s}}$ and $\mathrm{i} H_{\mathrm{c}}$ decrease with increasing lanthanum content. Table I lists the lattice parameters and Curie temperature, $T_{\mathrm{C}}$, of the $\tau$ phase. No significant changes in the lattice parameters were observed for these alloys, indicating that lan-

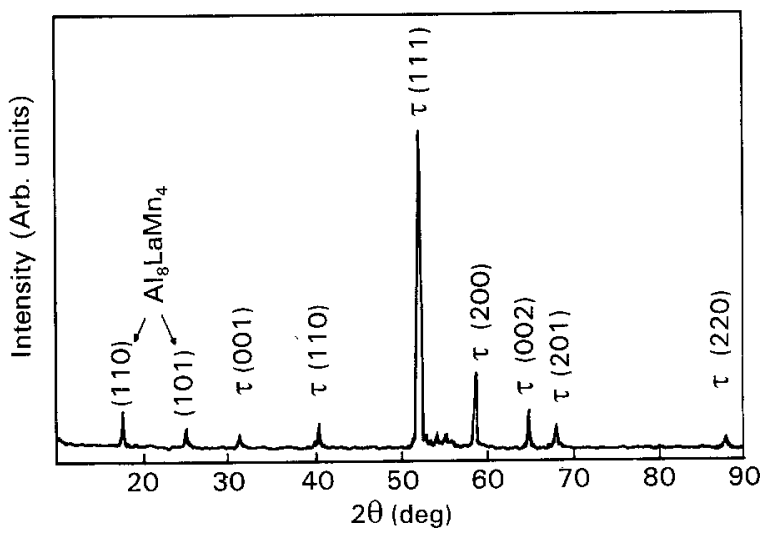

Figure 1 X-ray diffraction pattern of $\mathrm{MnAl}$ alloy with 0.3 at \% lanthanum content.

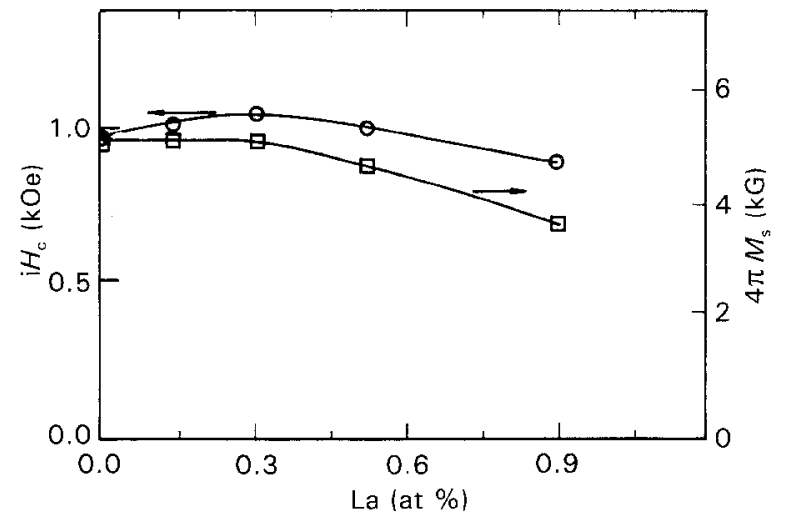

Figure 2 Magnetic properties versus lanthanum content of cast alloys; annealing temperature $=550^{\circ} \mathrm{C}$.

TABLE I Lattice parameters, $a, c$, and Curie temperature, $T_{C}$, of $\left(\mathrm{Mn}_{0.54} \mathrm{Al}_{0.46}\right)_{100-x} \mathrm{La}_{x}$ alloys, after annealing at $550^{\circ} \mathrm{C}$ for $1 \mathrm{~h}$

\begin{tabular}{llll}
\hline$x$ & $\begin{array}{l}a \\
(\mathrm{~nm})\end{array}$ & $\begin{array}{l}c \\
(\mathrm{~nm})\end{array}$ & $\begin{array}{l}T_{C} \\
\left({ }^{\circ} \mathrm{C}\right)\end{array}$ \\
\hline 0.00 & 0.278 & 0.360 & 380 \\
0.47 & 0.278 & 0.359 & 380 \\
1.00 & 0.277 & 0.359 & 378 \\
\hline
\end{tabular}
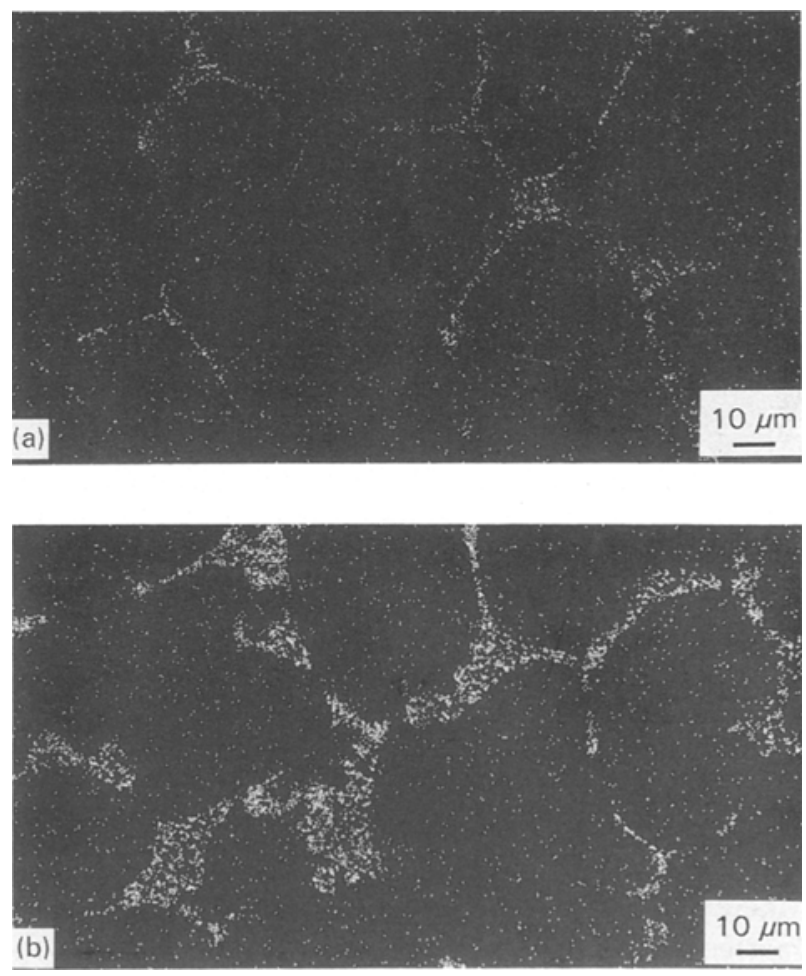

Figure 3 The lanthanum mapping micrographs of energy-dispersive X-ray spectroscopy for MnAlLa alloy with (a) 0.3 at \% lanthanum, and (b) 0.9 at \% lanthanum.

thanum atoms did not enter the crystal lattice of the $\tau$ phase. Therefore, the addition of lanthanum will form precipitates in the alloys. The change in the magnetic properties (Fig. 2) is due to the formation of lanthanum precipitates; for low lanthanum content samples, the fine precipitates inhibited the movement of 
the magnetic domain wall, and hence the $\mathrm{i} H_{\mathrm{c}}$ values were increased. The Curie temperature, $T_{\mathrm{C}}$, did not change on doping with lanthanum (Table I). Because $T_{\mathrm{C}}$ is primarily determined by the exchange interaction of manganese atoms and this exchange interaction depends mainly on interatomic distances [17], the stability of $T_{\mathrm{C}}$ is due to the lattice parameters of the magnetic $\tau$-phase remaining unchanged on lanthanum doping.

The composition distribution of lanthanum was determined by EDX in a scanning electron microscope, as shown in Fig. 3. A high intensity of lanthanum was observed at the grain boundaries. The segregation of lanthanum in the grain boundaries can be attributed to the very low solubility of lanthanum in the MnAl alloy.

Because the $\tau$-phase is the only ferromagnetic phase in the $\mathrm{Mn}-\mathrm{Al}$ alloy system, the saturation magnetization, $M_{\mathrm{s}}$, of the alloy is proportional to the amount of $\tau$-phase; this enables the formation of the $\tau$-phase to be detected by measuring the $M_{\mathrm{s}}$ [18]. Fig. 4 shows the time dependence of the $\varepsilon \rightarrow \tau$ transformations at an annealing temperature of $420^{\circ} \mathrm{C}$. It is seen that the formation of the $\tau$-phase was retarded by lanthanum doping. This is due to the lanthanum precipitates inhibiting the growth of the $\tau$-phase plate, which may be explained by the fact that the $\tau$-phase is formed by a shear transformation [9], which is a diffusionless process. Thus the $\tau$-phase plates grow in a definite direction depending on the slip system of the $\tau$-phase structure; the growth of $\tau$-phase will stop at these lanthanum precipitates and grain boundaries.

\subsection{Sintered magnets}

Sintered magnets were prepared by compacting the alloy powders with a particle size of about $15 \mu \mathrm{m}$ at a pressure of 5 ton $\mathrm{cm}^{-2}$, and sintering in vacuum at $1210^{\circ} \mathrm{C}$ for $15 \mathrm{~min}$. The magnetic properties of sin-

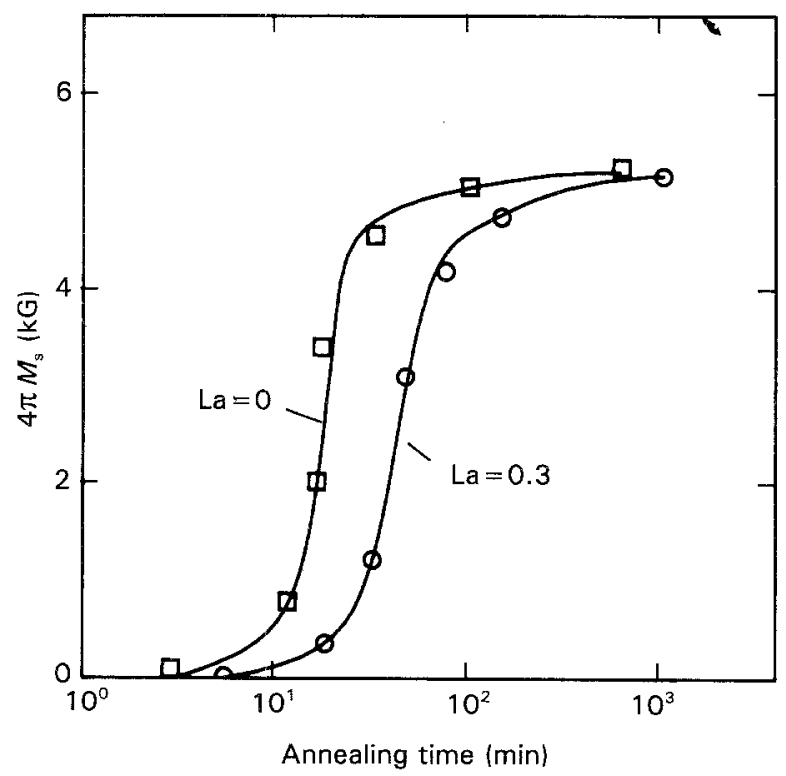

Figure 4 Variation of $4 \pi M_{\mathrm{s}}$ with annealing time of lanthanum-free and 0.3 at \% lanthanum-doped MnAl alloys.

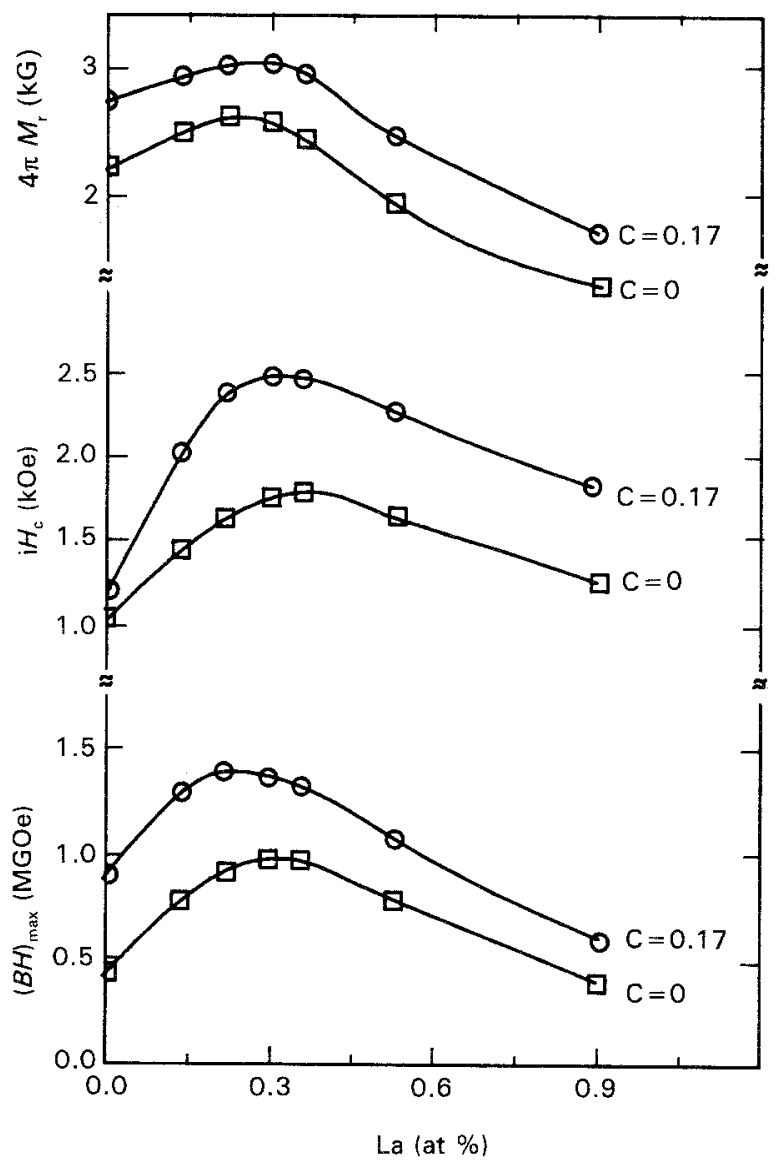

Figure 5 Magnetic properties versus lanthanum content of sintered $\left(\mathrm{Mn}_{0.54} \mathrm{Al}_{0.46}\right)_{100-x} \mathrm{La}_{x}$ and $\left(\mathrm{Mn}_{0.535} \mathrm{Al}_{0.448} \mathrm{C}_{0.017}\right)_{100-x} \mathrm{La} \mathrm{a}_{x}$ magnets.

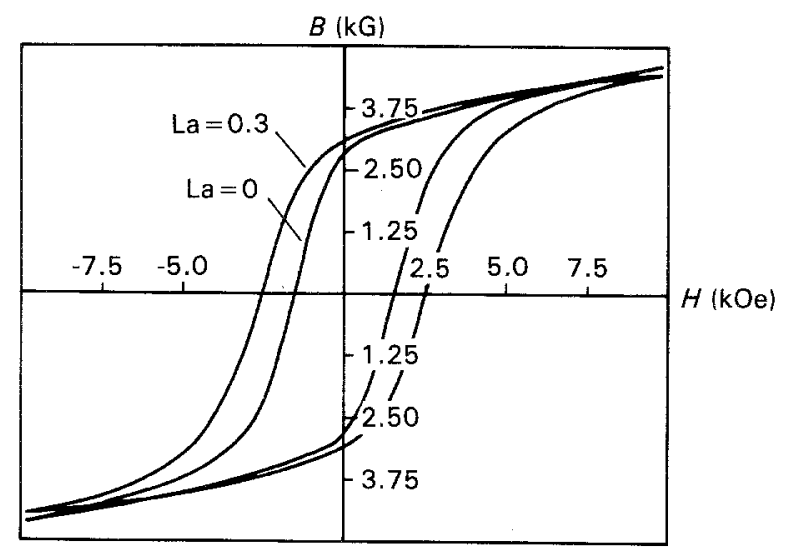

Figure 6 Hysteresis loops of $\mathrm{Mn}_{0.535} \mathrm{Al}_{0.448} \mathrm{C}_{0.017}$ and $\left(\mathrm{Mn}_{\mathbf{0 . 5 3 5}}\right.$ $\left.\mathrm{Al}_{0.448} \mathrm{C}_{0.017}\right)_{99.7} \mathrm{La}_{0.3}$ magnets.

tered $\left(\mathrm{Mn}_{0.54} \mathrm{Al}_{0.46}\right)_{100-x} \mathrm{La}_{x}$ and $\left(\mathrm{Mn}_{0.535} \mathrm{Al}_{0.448^{-}}\right.$ $\left.\mathrm{C}_{0.017}\right)_{100-x} \mathrm{La}_{x}$ magnets are shown in Fig. 5. The coercivity, $\mathrm{i} H_{\mathrm{c}}$, increases on increasing lanthanum content up to 0.36 at $\%$ La for the carbon-free sample and to 0.3 at $\% \mathrm{La}$ for the carbon-doped sample. The remanence, $4 \pi M_{\mathrm{r}}$, also increases due to the lanthanum doping. The hysteresis loops of lanthanum free and 0.3 at \% lanthanum content magnets (Fig. 6) show that for lanthanum-doped magnets, the increase in $H_{\mathrm{c}}$ leads to a slight increase in $4 \pi M_{\mathrm{r}}$. Because both the $\mathrm{i} H_{\mathrm{c}}$ and $4 \pi M_{\mathrm{r}}$ are increased by lanthanum doping, $(B H)_{\max }$ is greatly enhanced, and reaches its maximum value at about 0.3 at $\%$ lanthanum. 

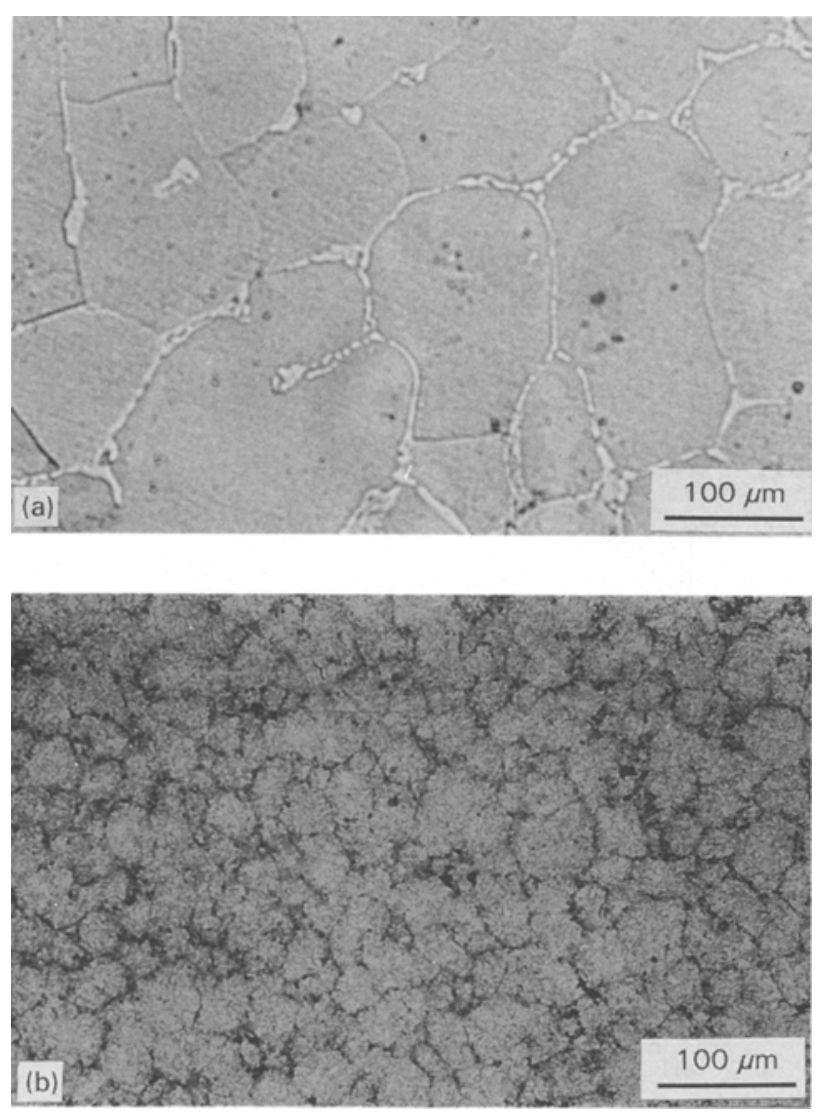

Figure 7 Optical micrographs of (a) cast $\mathrm{Mn}_{0.54} \mathrm{Al}_{0.46}$ alloy, and (b) sintered $\left(\mathrm{Mn}_{0.535} \mathrm{Al}_{0.448} \mathrm{C}_{0.017}\right)_{99.7} \mathrm{La}_{0.3}$ magnets.

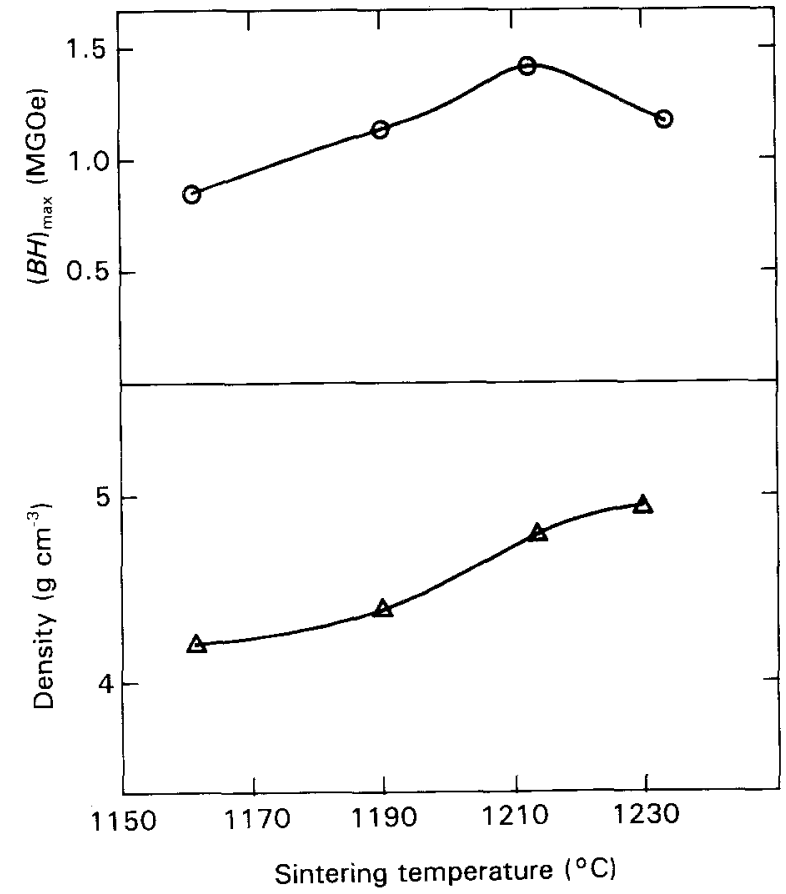

Figure 8 Variations of $(B H)_{\max }$ and density with sintering temperature of $\left(\mathrm{Mn}_{0.535} \mathrm{Al}_{0.448} \mathrm{C}_{0.017}\right)_{99.7} \mathrm{La}_{0.3}$ magnets.

It is obvious that the increase of $\mathrm{i} H_{\mathrm{c}}$ due to the addition of lanthanum in sintered magnets is much higher than that of cast alloys. Because the magnetic hardening of this magnet is primarily due to domainwall pinning by the defects and/or by the grain boundaries [19], the anomalous increase in coercivity is due to the lanthanum precipitations in the grain boundaries. The grain size of sintered magnets is much smaller than in the cast alloys; therefore, the effect of lanthanum precipitates on the coercivity is more pronounced in the sintered magnets. Optical micrographs of cast alloy and sintered magnets are shown in Fig. 7. The grain size is about 100 and $20 \mu \mathrm{m}$ for the cast alloys and the sintered magnets, respectively.

The variations of $(B H)_{\max }$ and sintering density with sintering temperature for $\left(\mathrm{Mn}_{0.535} \mathrm{Al}_{0.448^{-}}\right.$ $\left.\mathrm{C}_{0.017}\right)_{99.7} \mathrm{La}_{0.3}$ are shown in Fig. 8; the proper sintering conditions to yield a high $(B H)_{\max }$ value are $1210^{\circ} \mathrm{C}$ for $15 \mathrm{~min}$. Permanent magnet characteristics achieved in this study for the sintered isotropic lanthanum-doped magnets are $4 \pi M_{\mathrm{r}}=3100 \mathrm{G}, \mathrm{i} H_{\mathrm{c}}$ $=2500 \mathrm{Oe}$ and $(B H)_{\max }=1.4 \mathrm{MGOe}$. The sintering density is about $96 \%$ of the theoretical value $\left(5.15 \mathrm{~g} \mathrm{~cm}^{-3}\right)$.

\section{Conclusions}

Lanthanum-doped $\mathrm{Mn}-\mathrm{Al}$ and $\mathrm{Mn}-\mathrm{Al}-\mathrm{C}$ magnets have been made by conventional powder metallurgy processes. The addition of lanthanum increases the coercivity of the sintered magnets. The maximum increment in $(B H)_{\max }$ is about $16 \%$ at 0.3 at \% lanthanum doping. The best magnetic properties for the isotropic sintered samples in this study are $4 \pi M_{\mathbf{r}}$ $=3100 \mathrm{G}, \mathrm{i}_{\mathrm{c}}=2500 \mathrm{Oe}$, and $(\mathrm{BH})_{\max }=1.4 \mathrm{MGOe}$. The improved magnetic properties of the sintered lanthanum-doped magnets might be due to the smaller grain sizes and the lanthanum precipitates in the grain boundaries.

\section{Acknowledgement}

This work was supported by the National Science Council of Taiwan under Contract NSC-81-0405E-002-24.

\section{References}

1. H. KONO, J. Phys. Soc. Jpn 13 (1958) 1444

2. A. J. J. KOCH, P. HOKKELING, M. G. V. D. STERG and K. J. DEvoS, J. Appl. Phys. 31 (1960) 75S.

3. J. P. JAKUBOVICS and T. W. JOLLY, Phys. B 86 (1976) 1357.

4. J. J. VAN DEN, BROEK, H. DONKERSLOOT, G. VAN TENDELOO and J. VAN LANDUY T, Acta Metall. 27 (1979) 1497

5. J.VAN LANDUYT, G. VAN TENDELOO, J. J. VAN DEN BROEK and H. DONKERSLOOT, J. Magn. Magn. Mater. 15-18 (1980) 1451.

6. M. A. BOHLMANN, J. C. KOO and J. H. WISE, J. Appl. Phys. 52 (1981) 2542.

7. Y. HARA, R. C. O'HANDLEY and N, J, GRANT, J, Magn. Magn. Mater. 54-57 (1986) 1077.

8. Ye. Z. VINTAYKIN, V. A. UDOVENKO, I. S. BELYATSKAYA, N. N. LUARSABISHVILI and S. YU. MAKUSHEV, Fiz. Metal. Metalloved. 38 (1974) 398.

9. S. KOHIMA, T. OHTANI, N. KATO, K. KOJIMA, Y SAKAMOTO, I. KONNO, M. TSUKAHARA and T. KUBO, "AIP Conference Proceedings", Vol. 24 (American Institute of Physics, Inc., New York, 1974) p. 768.

10. T. OTANI, N. KATO, K. KOJIMA, Y, SAKAMOTO, I. KONNO, M. TSUKAHARA and T. KUBO, IEEE Trans. Magn. 13 (1977) 1328.

11. Ya. S. SHUR, K. P. RODINOV, D. K. BULYCHEV, M. I OLEVNIK, L. V. SMIRNOV, K. S. KANDAVROVA, L. M. 
MAGAT and W. N. BYHANOVA, Fiz. Metal. Metalloved. 23 (1967) 338.

12. H. YAMAMOTO, US Pat. 3661567 , May 1972

13. J. H. HUANG, P. C. KUO, Mater. Sci. Eng. B 14 (1992) 75.

14. K. NARITA, T, SASA K I and Y. SETOGUCHI, Jpn. J. Appl. Phys. 9 (1970) 1536.

15. M. SugiharA and J. TSUboYA, J. Appl. Phys. 33 (1962) 1338.

16. T. KAWAGUCHI, M. NAGAKURA, K. KAMINO and S. YOSHIZAWA, J. Jpn Inst. Metals 28 (1964) 384.
17. B. D. CUllity, "Introduction to Magnetic Materials" (Addison-Wesley, New York, 1972) p. 135.

18. J. H. HUANG and P. C. KUO, Mater. Sci. Eng. B, to be published.

19. J. D. Livingston, J. Appl..Phys. 52 (1981) 2544.

Received 4 March 1993

and accepted 19 January 1994 